\title{
Lung Disease and Hypertension
}

\author{
Yuki Imaizumi Kazuo Eguchi Kazuomi Kario \\ Division of Cardiovascular Medicine, Department of Medicine, Jichi Medical University, \\ Shimotsuke, Japan
}

\section{Key Words}

Chronic obstructive pulmonary disease - Cardiovascular disease - Inflammation ·

Sympathetic overactivity

\begin{abstract}
Chronic obstructive pulmonary disease (COPD) patients are at a high risk of developing cardiovascular diseases. Airflow limitation is a predictor of future risks of hypertension and cardiovascular events. COPD is now understood as a systemic inflammatory disease, with the focus on inflammation of the lungs. An association between inflammation and sympathetic overactivity has also been reported. In this article, we review the association between chronic lung disease and the risks of hypertension, cardiovascular morbidity, the underlying mechanisms, and the therapeutic approach to hypertension and cardiovascular diseases in patients with lung diseases.

(c) 2015 S. Karger AG, Basel
\end{abstract}

\section{Introduction}

It has increasingly been recognized that the incidence of cardiovascular events is high in patients with chronic lung disease, represented by chronic obstructive pulmonary disease (COPD) [1, 2]. A number of population studies have shown that airflow limitation as measured by the forced expiratory volume in $1 \mathrm{~s}\left(\mathrm{FEV}_{1}\right)$ or the $\mathrm{FEV}_{1}$ /forced vital capacity ratio is a predictor of future risks of hypertension [3] and cardiovascular events [4]. It has recently been reported that COPD is associated with a high risk of congestive heart failure, ischemic heart disease, arrhythmia, stroke, hypertension, and peripheral artery disease [5]. The rates of hospitalization due to cardiovascular diseases and mortality among COPD patients were found to be twice those of non-COPD patients [6]. The other review described that for every $10 \%$ decrease in $\mathrm{FEV}_{1}$, all-cause mortality increases by $14 \%$, cardiovascular mortality increases by $28 \%$, and nonfatal coronary events increase by almost $20 \%$ [4]. 
Imaizumi et al.: Lung Disease and Hypertension

COPD shares some risk factors with cardiovascular diseases such as aging and smoking. However, COPD was shown to be an independent risk factor for the development of cardiovascular diseases $[6,7]$. COPD has recently been recognized as a systemic inflammatory disease, in contrast to the previous view of COPD as a pure lung disease [8]. We hereby review the association between chronic lung diseases represented by COPD and the risk for cardiovascular morbidity and the therapeutic approach to cardiovascular diseases in patients with lung diseases.

\section{Smoking, COPD, and Hypertension}

COPD is an inflammatory response of the lungs to pollutants, mainly tobacco smoke [9]. The odds ratio for COPD in smokers is 2.92 (95\% confidence interval 2.65-3.20) [10]. Both the smoking rate and the prevalence of COPD are high in Asia [11]. Smoking is an established risk factor for cardiovascular diseases. However, in COPD patients, it is difficult to distinguish whether their increased risk of cardiovascular disease is due to smoking or due to COPD [2]. COPD, hypertension, and cardiovascular disease are strongly linked with each other, and it is very hard to adjust smoking statistically [2]. Smoking is a risk factor for both COPD and cardiovascular disease.

\section{COPD and Systemic Inflammation}

COPD has been confirmed to be one of the systemic inflammatory diseases. Inflammation plays a central role in the pathogenesis of COPD. As part of the chronic inflammatory process, the cytokines tumor necrosis factor-alpha (TNF- $\alpha$ ) and interleukin (IL)-6 are known to be elevated in COPD patients [8]. The levels of inflammatory mediators such as TNF- $\alpha$, IL-6 and C-reactive protein (CRP) are elevated not only at the time of acute exacerbation but also when the disease is stable. Serum CRP has been shown to be a marker of cardiovascular morbidity and mortality [12].

Inflammatory mediators were compared between COPD patients and non-COPD patients with or without a smoking history [13]: the levels of the white blood cell count, TNF- $\alpha$, and IL-8 were the highest in the COPD patients, as were the levels of fibrinogen, IL-6, and highsensitivity CRP. Of note, the white blood cell count, TNF- $\alpha$, and IL-8 levels were also elevated in the non-COPD patients who were smokers compared to the nonsmoking non-COPD patients. Thus, COPD is clearly a systemic inflammatory disease, with the focus on inflammation of the lungs.

An association between increased parameters of inflammation and sympathetic overactivity was reported in both a healthy young population [14] and an elderly population without heart disease [15]. An animal study revealed that parasympathetic nervous system activity may have anti-inflammatory effects [16].

COPD patients are also very prone to infections. It was reported that approx. $50 \%$ of acute exacerbations of COPD are caused by Haemophilus influenzae, Moraxella catarrhalis, Streptococcus pneumoniae or Pseudomonas aeruginosa infections [17]. Bacteria such as Chlamydia pneumoniae (CP) contribute to the progression of atherosclerosis [18], and approx. 4-16\% of COPD exacerbations may be due to infection by CP [19]. CP causes atherosclerosis through inflammation, with an increased production of inflammatory cytokines (IL-1 $\beta$, IL-6, IL-8, and TNF- $\alpha$ ), chemokines, and reactive oxygen species [18]. Being prone to infections may also be a potential risk for atherosclerosis due to the frequent and prolonged inflammation via sympathetic activation. 
Imaizumi et al.: Lung Disease and Hypertension

\section{COPD and Cardiovascular Diseases}

In Western countries, cardiovascular diseases are the second highest cause of mortality among COPD patients after respiratory failure. The rate of cardiovascular mortality in COPD patients is about $20-30 \%$ of all-cause mortality, and the rate of sudden death is as high as $17 \%$ in men and $11 \%$ in women [20]. It is known that the incidence of ischemic heart disease is high in COPD patients [21]; however, it widely differs from 4.7 to $60 \%$. Among COPD patients hospitalized in 1998, the prevalence of congestive heart failure was $24.4 \%$ and the prevalence of atrial fibrillation (Af) was 14.3\%. However, in a matched non-COPD cohort, the prevalence of congestive heart failure was $13.5 \%$ and that of Af was $10.4 \%$, and these values are significantly higher in COPD patients [22].

Another study found that the risk of new Af was 1.8 times higher for $\mathrm{FEV}_{1}$, between 60 and $80 \%$ of predicted, compared with $\mathrm{FEV}_{1} \geq 80 \%$, after adjustment for age, sex, smoking, blood pressure (BP), diabetes, and body mass index [23]. It was also reported that diastolic heart failure is frequently seen in COPD patients. In mild to moderate COPD patients, the severity of emphysema and decreased $\% \mathrm{FEV}_{1}\left(\mathrm{FEV}_{1} /\right.$ forced vital capacity) was associated with the level of left ventricular diastolic dysfunction [24]. The underlying mechanisms of this may be hyperinflation of the lungs (which results in elevated intrathoracic pressure and decreased preload) and chronic ischemia of the cardiac muscle. COPD is, therefore, one of the potential risk factors for cardiovascular events.

\section{COPD, Pulmonary Hypertension, and Right-Sided Heart Failure}

Pulmonary hypertension (PH) is frequently seen in COPD patients. The development of $\mathrm{PH}$ is associated with poor prognosis [25] and may progress to right-sided heart failure [26]. $\mathrm{PH}$ in COPD patients is caused by the loss of alveolar remodeling of the pulmonary vessels by chronic hypoxia and inflammation, decreases in the levels of endothelial vasodilators such as nitric oxide, and vasospasm caused by factors such as endothelin-1 [26]. These changes are even seen in smokers with normal lung function, and endothelial dysfunction from cigarette smoking may be the primary step in the development of PH in COPD patients.

With regard to the development of right-sided heart failure, it has recently been reported that right ventricular end-diastolic volume (RVEDV) was reduced in subjects with COPD compared to controls, and the RVEDV and right ventricular stroke volume was lowered as the severity of COPD increased. A greater percentage of emphysema was also associated with lower RVEDV and stroke volume [27]. In the acute exacerbation of COPD, pulmonary pressure is further elevated along with the worsening of hypoxia, which could result in right-sided heart failure [28].

\section{Sleep Apnea and COPD}

Obstructive sleep apnea syndrome is an independent risk factor for hypertension and cardiovascular disease [29]. The coexistence of obstructive sleep apnea syndrome and COPD is common, and it is called overlap syndrome [30]. In patients with overlap syndrome, nocturnal oxygen desaturation is severe and the prevalence of PH is very high. In acute exacerbation in patients with overlap syndrome, noninvasive pressure support is known to be beneficial [30]. However, the evidence is limited to whether the pressure support therapy is effective in the chronic setting of COPD patients without obstructive sleep apnea [30]. 
Fig. 1. Exaggerated BP variability in patients with pneumoconiosis. In the pneumoconiosis patients, the daytime SBP level tended to be lower $(p=0.07)$, whereas the CV in 24-hour SBP $(\mathrm{p}<0.05)$ and diastolic BP $(p<0.001)$ were significantly higher than in the control subjects. Adopted from Imaizumi et al. [33]. DBP = Diastolic BP.

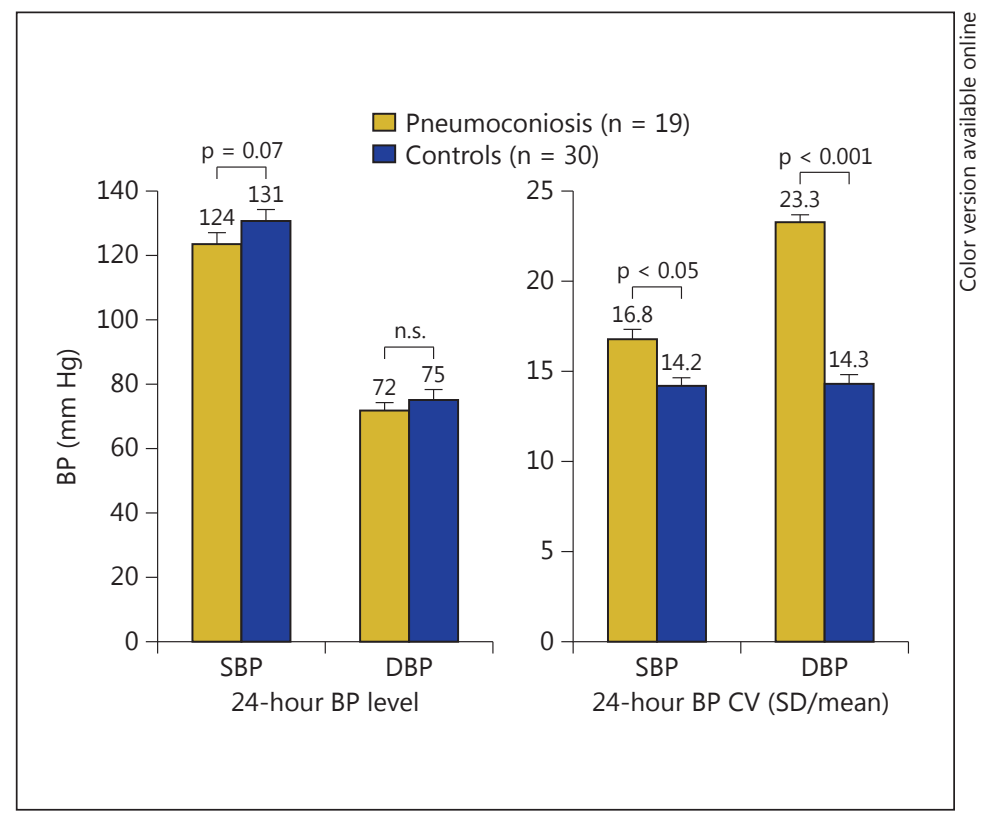

\section{Chronic Hypoxia and the Hemodynamic System}

Chronic hypoxia is a risk factor for hypertension and cardiovascular disease [29, 31], but the underlying mechanism is unclear. Increased BP variability has been reported to be associated with an adverse cardiovascular prognosis in hypertensive patients [32]. We showed that chronic hypoxia was associated with abnormal BP and pulse rate (PR) variability in patients with pneumoconiosis. We recruited 19 patients with pneumoconiosis and 30 ageand BP level-matched control subjects from the Japan Morning Surge Home Blood Pressure (J-HOP) study. We used simultaneous pulse oximetry and ambulatory BP monitoring for all subjects and evaluated their BP levels and variability by determining the standard deviation (SD) and coefficient of variation (CV) of the BP data.

We found that in the patients with pneumoconiosis, although the daytime systolic BP (SBP) level tended to be lower ( $p=0.07)$, the CV values for 24-hour SBP $(p<0.05)$ and diastolic BP ( $p<0.001)$ were significantly higher than those in the control subjects (fig. 1$)$. The median daytime pulse oximetry oxygen saturation was inversely associated with the mean $(\mathrm{r}=-0.30 ; \mathrm{p}<0.01)$ and SD $(\mathrm{r}=-0.38 ; \mathrm{p}<0.001)$ of daytime SBP. The median nighttime pulse oximetry oxygen saturation $(r=-0.55 ; \mathrm{p}<0.001)$ was inversely associated with the mean nighttime PR $(r=0.51 ; \mathrm{p}<0.001)$, and it was associated with the CV of nighttime SBP.

In the same study, a similar association between hypoxia and BP variability was also seen by using the arterial blood gas results as a parameter of hypoxia. The partial pressure of oxygen in arterial blood gas $\left(\mathrm{PaO}_{2}\right)$ was inversely associated with the CV of daytime SBP $(\mathrm{r}=$ $-0.24 ; \mathrm{p}<0.05$ ).

Thus, exaggerated BP variability was seen in patients with pneumoconiosis, and the measures of hypoxia were associated with large fluctuations in ambulatory BP and PR [33]. As increased BP variability is associated with poor cardiovascular prognosis in hypertensive patients, patients with severe lung diseases should be considered a high-risk group for cardiovascular diseases in terms of their high BP variability. 
Imaizumi et al.: Lung Disease and Hypertension

\section{Air Pollution and Hypertension}

It has increasingly been recognized that the concentration of air pollutants may contribute to BP elevation and cardiovascular diseases. The association between the concentration of fine particulate air pollutants and increased BP was reported in a multiethnic study [34]. We have recently shown that the concentration of fine particulate matter with a diameter $<2.5 \mu \mathrm{m}$ (PM2.5) was associated with the home BP level at low temperatures [35]. We analyzed home BP data for 91 consecutive days in 40 hypertensive individuals living on Munakata Ohshima Island, a small island in Japan. We found that PM2.5 alone was not correlated with home BP levels, but a high PM2.5 concentration plus low temperature was associated with a 1.6-fold increased likelihood of morning hypertension $(\mathrm{p}<0.001)$. In addition, the coexistence of low temperature and high PM2.5 was associated with a 2.3 -fold increased likelihood of morning hypertension $(\mathrm{p}<0.001)$ compared to a high-temperature and low-PM2.5 condition. This indicates that PM2.5 could be a modifying factor for BP elevation at low temperatures. Not only individual lung function but also environmental and meteorological factors are important for exaggerated BP elevation [35].

\section{Mechanism of Cardiovascular Risk in Patients with Lung Diseases}

The pathophysiology of elevated cardiovascular risk in patients with cardiovascular events is multifactorial (table 1), but the overactivity of the sympathetic nervous system may play a central role as an underlying mechanism [36]. Both COPD and chronic lung disease are associated with sympathetic nervous system activation (fig. 2) due to systemic inflammation [14-16], hypoxia [29], lower baroreflex sensitivity [37], inhibition of pulmonary stretch receptors [38], and elevated muscle sympathetic nerve activity [39]. Vascular stiffness was also reported to be elevated in COPD patients [37, 40], and the lower baroreflex sensitivity due to vascular stiffness [37] may also result in augmented sympathetic nerve activity. Air pollution may also be a risk for decreased arterial compliance [34] and morning hypertension [35], both of which may worsen atherosclerosis.

A number of studies have reported that BP variability was elevated in patients with lung diseases. In a recent report, the speed of fluctuations in SBP was associated with the severity of airflow limitation in COPD patients [41]. In patients with pneumoconiosis, a restrictive lung disease, the inhibition of pulmonary stretch receptors might have activated the sympathetic nervous system and resulted in exaggerated BP variability [33].

\section{Therapy for Cardiovascular Diseases in COPD Patients}

The comorbidities of COPD and lung complications can affect the severity of COPD and the quality of life of the patients, and thus the prevention and treatment of these comorbidities and complications are important [42].

\section{Ischemic Heart Disease}

$\beta$-Blockers are useful in the treatment of patients with angina pectoris and myocardial infarction, even in patients with COPD. A large cohort study of COPD patients showed that the advantage of using selective $\beta_{1}$-blockers exceeded the disadvantage, even in COPD patients with ischemic heart disease [43]. The presence of COPD is no longer a reason for avoiding the use of $\beta_{1}$-blockers in patients with ischemic heart disease. 
Fig. 2. Mechanism of cardiovascular risk in patients with chronic lung diseases. The pathophysiology of elevated cardiovascular risk in patients with chronic lung diseases is multifactorial. The overactivity of the sympathetic nervous system due to systemic inflammation, hypoxia, air pollution, lower baroreflex sensitivity, inhibition of pulmonary stretch receptors, lower activity of parasympathetic nervous system, and elevated muscle sympathetic nerve activity may play central roles with or without atherosclerosis, resulting in hypertension and elevated BP variability.

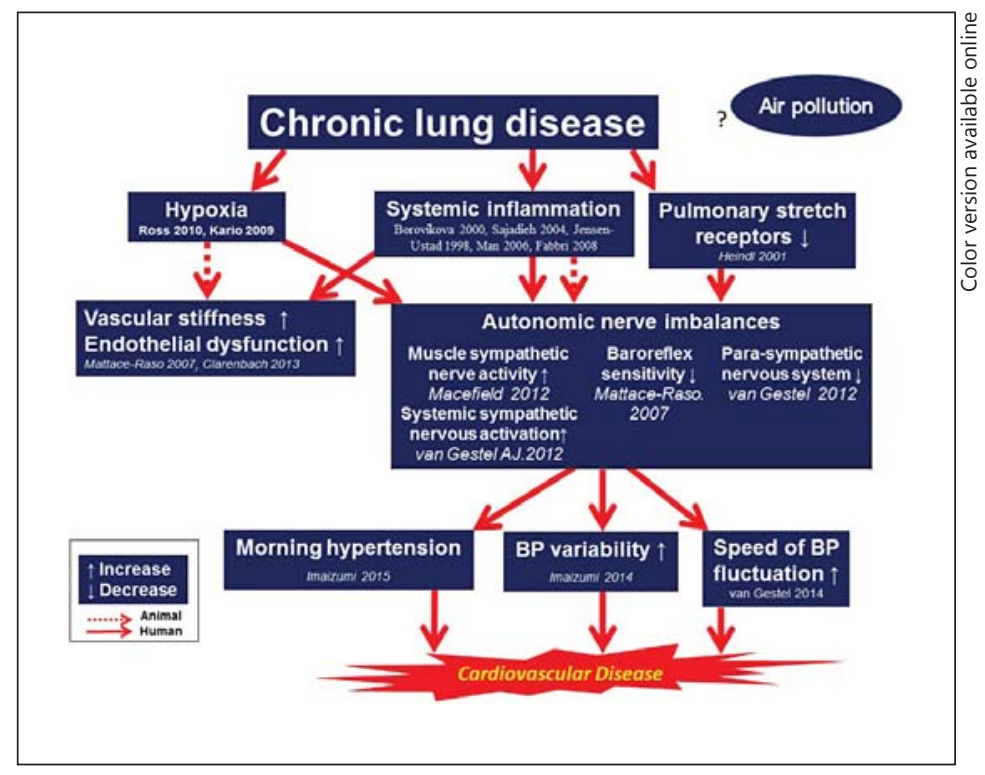

Table 1. Studies that may explain the mechanism underlying chronic lung diseases and elevated cardiovascular risks

\begin{tabular}{|c|c|c|c|c|}
\hline $\begin{array}{l}\text { Ref. } \\
\text { No. }\end{array}$ & Authors & Year & Journal & Main result(s) \\
\hline 14 & Jensen-Urstad et al. & 1998 & J Intern Med & Heart rate variability was related to leukocyte count \\
\hline 16 & Borovikova et al. & 2000 & Nature & $\begin{array}{l}\text { Vagus nerve stimulation attenuated the systemic inflammatory response to } \\
\text { endotoxin in rats }\end{array}$ \\
\hline 38 & Heindl et al. & 2001 & $\begin{array}{l}\text { Am J Respir Crit } \\
\text { Care Med }\end{array}$ & $\begin{array}{l}\text { Activity of pulmonary stretch receptors was decreased, and sympathetic } \\
\text { activity was increased in chronic respiratory failure }\end{array}$ \\
\hline 15 & Sajadieh et al. & 2004 & Eur Heart J & $\begin{array}{l}\text { Increased heart rate and reduced heart rate variability are associated with } \\
\text { subclinical inflammation in healthy middle-aged and elderly subjects }\end{array}$ \\
\hline 12 & Man et al. & 2006 & Thorax & CRP was associated with mortality in mild-to-moderate COPD \\
\hline 37 & Mattace-Raso et al. & 2007 & J Hypertens & $\begin{array}{l}\text { Sensitivity of the baroreflex was decreased, vascular stiffness and } \\
\text { endothelial dysfunction was augmented in COPD }\end{array}$ \\
\hline 34 & Auchincloss et al. & 2008 & $\begin{array}{l}\text { Environ Health } \\
\text { Perspect }\end{array}$ & $\begin{array}{l}\text { Air pollution was associated with vascular stiffness and endothelial } \\
\text { dysfunction in COPD }\end{array}$ \\
\hline 8 & Fabbri et al. & 2008 & Eur Respir J & COPD is a systemic inflammation disease \\
\hline 29 & Kario & 2009 & Hypertens Res & $\begin{array}{l}\text { Intermittent hypoxia was followed by BP surge in patients with obstructive } \\
\text { sleep apnea }\end{array}$ \\
\hline 31 & Ross et al. & 2010 & Am J Hypertens & $\begin{array}{l}\text { Prolonged hypoxia in early stage of life was associated with atherosclerosis } \\
\text { in an animal model }\end{array}$ \\
\hline 39 & Macefield & 2012 & Front Physiol & Muscle sympathetic nerve activity was increased in respiratory diseases \\
\hline 36 & van Gestel et al. & 2012 & Discov Med & $\begin{array}{l}\text { Sympathetic activity was increased, and parasympathetic activity was } \\
\text { decreased in COPD }\end{array}$ \\
\hline 40 & Clarenbach et al. & 2013 & Eur Respir J & $\begin{array}{l}\text { Vascular stiffness was elevated, endothelial dysfunction was augmented in } \\
\text { COPD }\end{array}$ \\
\hline 33 & Imaizumi et al. & 2014 & Am J Hypertens & BP variability was exaggerated in patients with pneumoconiosis \\
\hline 41 & van Gestel et al. & 2014 & Heart Lung Circ & Speed of BP fluctuation was elevated in COPD \\
\hline 35 & Imaizumi et al. & 2015 & Clin Exp Hypertens & $\begin{array}{l}\text { High particulate matter at } 2.5-\mu \mathrm{m} \text { concentration and cold temperature } \\
\text { existing together is associated with morning hypertension }\end{array}$ \\
\hline
\end{tabular}


Imaizumi et al.: Lung Disease and Hypertension

\section{Hypertension}

Hypertension is the most frequently seen comorbidity in COPD patients, and its effect on the prognosis is apparent. Even in COPD patients, antihypertensive treatment should be performed following guidelines such as the Japanese Society of Hypertension Guidelines for the Management of Hypertension (JSH2014) [44]. The consensus regarding each antihypertensive drug can be described as follows.

Diuretics and $\alpha$-Blockers

There are no data yet from a clinical trial with patients with low respiratory function.

Calcium Channel Blockers

We do not yet have data to recommend calcium channel blockers for hypertensive COPD patients. However, there is a study showing that the muscle contraction in tracheobronchial smooth muscle was decreased after nifedipine treatment in patients with chronic stable asthma and abnormal lung function [45]. This result suggests that an orally administered calcium channel blocker has a bronchodilating effect. The effect may reinforce the bronchodilator effect of $\beta$-agonists.

\section{Renin-Angiotensin System Blocker}

There are no reports stating that a renin-angiotensin system blocker was found to be harmful to COPD patients. From the point of view of prevention of cardiovascular disease and amelioration of the prognosis, there may be no problem to use renin-angiotensin system blockers in antihypertensive therapy in COPD patients. There are also no reports from a large-scale randomized trial showing that using angiotensin-converting enzyme blockers for patients with respiratory complications resulted in worsening of the cough or bronchospasm.

\section{$\beta$-Blockers}

In the JSH2014 guidelines [44], it is stated that $\beta$-blockers must be prescribed carefully for COPD patients and that they are contraindicated for patients with asthma. Carvedilol is a nonselective $\beta$-blocker, but it has anti-inflammatory and vasodilating effects, and it may improve the atherosclerosis of COPD patients and decrease the rate of cardiovascular events. Nebivolol, which is not yet used in Japan, has $\beta_{1}$-selectivity. It increases the production of nitric oxide and has a vasodilating effect. It is possible that nebivolol may have some beneficial effect on COPD patients by decreasing their cardiovascular risk [46]. Three randomized controlled trials have examined $\beta$-blockers with COPD and heart failure and demonstrated that cardioselective $\beta$-blockers were well tolerated in such patients [47-49]. However, it has been reported that, regardless of the presence of selectivity of the $\beta$-receptors, the mortality and the rate of the exacerbation of COPD patients decreased with the use of $\beta$-blockers; the study authors did not mention any differences among races [50]. In addition, an association between the use of $\beta$-blockers and improved survival was reported in COPD patients with heart failure, myocardial infarction, vascular disease, and hypertension in a recently published review [51]. The pooled relative risk of mortality related to $\beta$-blockers in COPD patients was 0.69 (95\% CI 0.62-0.78) in a recent meta-analysis [52], which indicates that $\beta$-blockers are protective in patients with COPD.

The data regarding the treatment outcomes of each of the antihypertensive drugs are insufficient. At present, we should manage antihypertensive treatment regardless of the presence of COPD following the appropriate guidelines. 
Imaizumi et al.: Lung Disease and Hypertension

\section{Heart Failure}

It is thought that many patients with heart failure are undertreated due to the presence of COPD. Heart failure can be divided into (a) heart failure with preserved ejection fraction and (b) heart failure with reduced ejection fraction as a result of systemic inflammation. A specific treatment for heart failure with preserved ejection fraction has not been established, but for heart failure with reduced ejection fraction, it is recommended that it be treated with $\beta_{1}$-selective blockers regardless of COPD to improve the cardiovascular prognosis [53]. It was reported that in patients with both heart failure and COPD, treatment by bisoprolol resulted in decreased $\mathrm{FEV}_{1}$, but it did not produce any worsening of the symptoms or the quality of life [49]. Selective $\beta_{1}$-blockers are more effective than nonselective $\beta$-blockers in the treatment of heart failure in COPD patients.

Noninvasive ventilation, when added to conventional therapy, improves the outcome of patients with acute respiratory failure that is due to hypercapnic exacerbation of COPD or heart failure in situations of acute pulmonary edema [54]. Biphasic positive airway pressure can improve the right ventricular function and decrease plasma levels of natriuretic peptides [55]. Combined approaches are needed to manage these comorbidities of COPD such as heart failure.

\section{Pulmonary Hypertension}

Diuretics are used in the treatment of PH. However, diuretics might be harmful in patients with severe right-sided heart failure with low cardiac output, because diuretics may further decrease cardiac output. The efficacy of digitalis on the right side of the heart is lower than that on the left side, and there is no consensus on the use of digitalis for patients with rightsided heart failure. In addition, there is no data showing that PH-specific vasodilators such as phosphodiesterase-5 inhibitors, endothelin receptor antagonists, and prostanoids are useful for treating PH due to COPD. They may nonselectively dilate the vessels in hypoventilated areas of the lung and worsen hypoxemia [26]. As mentioned above, biphasic positive airway pressure can improve the right ventricular function [55].

\section{Conclusion}

Patients with chronic lung disease, represented by COPD, are a high-risk group for cardiovascular diseases. The Global Initiative for Chronic Obstructive Lung Disease (GOLD) 2014 [56] emphasizes that it is important to pay attention to both the presence of cardiovascular diseases in the treatment of COPD and the presence of COPD in the treatment of cardiovascular diseases. Increased BP variability may be one of the underlying mechanisms behind the relationship between lung disease and increased risk of cardiovascular diseases. Further accumulation of evidence is needed to better understand these two diseases and especially how they are linked clinically. The smoking rate and prevalence of COPD is still high in Asia. It is very important to focus on those risks and future cardiovascular risk, especially in Asia, in order to better treat and improve the prognosis of COPD patients.

\section{References}

1 Sin DD, Anthonisen NR, Soriano JB, Agusti AG: Mortality in COPD: role of comorbidities. Eur Respir J 2006;28: 1245-1257.

2 Maclay JD, MacNee W: Cardiovascular disease in COPD: mechanisms. Chest 2013;143:798-807.

-3 Engström G, Wollmer P, Valind S, Hedblad B, Janzon L: Blood pressure increase between 55 and 68 years of age is inversely related to lung function: longitudinal results from the cohort study 'Men born in 1914'. J Hypertens 2001;19:1203-1208. 
Imaizumi et al.: Lung Disease and Hypertension

4 Sin DD, Man SF: Chronic obstructive pulmonary disease as a risk factor for cardiovascular morbidity and mortality. Proc Am Thorac Soc 2005;2:8-11.

5 Müllerova H, Agusti A, Erqou S, Mapel DW: Cardiovascular comorbidity in COPD: systematic literature review. Chest 2013;144:1163-1178.

6 Sidney S, Sorel M, Quesenberry CP Jr, DeLuise C, Lanes S, Eisner MD: COPD and incident cardiovascular disease hospitalizations and mortality: Kaiser Permanente Medical Care Program. Chest 2005;128:2068-2075.

7 Gan WQ, Man SF, Senthilselvan A, Sin DD: Association between chronic obstructive pulmonary disease and systemic inflammation: a systematic review and a meta-analysis. Thorax 2004;59:574-580.

8 Fabbri LM, Luppi F, Beghé B, Rabe KF: Complex chronic comorbidities of COPD. Eur Respir J 2008;31:204-212.

9 MacNee W: Pathogenesis of chronic obstructive pulmonary disease. Proc Am Thorac Soc 2005;2:258-266.

$>10$ Forey B, Thornton A, Lee P: Systematic review with meta-analysis of the epidemiological evidence relating smoking to COPD, chronic bronchitis and emphysema. BMC Pulm Med 2011;11:36.

11 Burney P, Jarvis D, Perez-Padilla R: The global burden of chronic respiratory disease in adults. Int J Tuberc Lung Dis 2015;19:10-20.

12 Man SFP, Connett JE, Anthonisen NR, Wise RA, Tashkin DP, Sin DD: C-reactive protein and mortality in mild to moderate chronic obstructive pulmonary disease. Thorax 2006;61:849-853.

13 Agustí A, Edwards LD, Rennard S, MacNee W, Tal-Singer R, Miller BE, Vestbo J, Lomas DA, Calverley PMA, Wouters E, Crim C, Yates JC, EK. S, Coxson HO, Bakke P, Mayer RJ, Celli B; Evaluation of COPD Longitudinally to Identify Predictive Surrogate Endpoints (ECLIPSE) Investigators: Persistent systemic inflammation is associated with poor clinical outcomes in COPD: a novel phenotype. PLoS One 2012;7:e37483.

$>14$ Jensen-Urstad M, Jensen-Urstad K, Ericson M, Johansson J: Heart rate variability is related to leucocyte count in men and to blood lipoproteins in women in a healthy population of 35-year-old subjects. J Intern Med 1998; 243:33-40.

15 Sajadieh A, Nielsen OW, Rasmussen V, Hein HO, Abedini S, Hansen JF: Increased heart rate and reduced heartrate variability are associated with subclinical inflammation in middle-aged and elderly subjects with no apparent heart disease. Eur Heart J 2004;25:363-370.

-16 Borovikova LV, Ivanova S, Zhang M, Yang H, Botchkina G, Watkins LR, Wang H, Abumrad N, Eaton JW, Tracey KJ: Vagus nerve stimulation attenuates the systemic inflammatory response to endotoxin. Nature 2000;405: 458-462.

17 Parameswaran GI, Murphy TF: Chronic obstructive pulmonary disease. Drugs Aging 2009;26:985-995.

18 Di Pietro M, Filardo S, De Santis F, Mastromarino P, Sessa R: Chlamydia pneumoniae and oxidative stress in cardiovascular disease: state of the art and prevention strategies. Int J Mol Sci 2014;16:724-735.

-19 Choroszy-Król I, Frej-Mądrzak M, Hober M, Sarowska J, Jama-Kmiecik A: Infections caused by Chlamydophila pneumoniae. Adv Clin Exp Med 2014;23:123-126.

-20 Celli B, Vestbo J, Jenkins CR, Jones PW, Ferguson GT, Calverley PM, Yates JC, Anderson JA, Willits LR, Wise RA; Investigators of the TORCH Study: Sex differences in mortality and clinical expressions of patients with chronic obstructive pulmonary disease. The TORCH experience. Am J Respir Crit Care Med 2011;183:317-322.

-21 Johnston AK, Mannino DM, Hagan GW, Davis KJ, Kiri VA: Relationship between lung function impairment and incidence or recurrence of cardiovascular events in a middle-aged cohort. Thorax 2008;63:599-605.

-22 Mapel DW, Dedrick D, Davis K: Trends and cardiovascular co-morbidities of COPD patients in the Veterans Administration Medical System, 1991-1999. COPD 2005;2:35-41.

23 Buch P, Friberg J, Scharling H, Lange P, Prescott E: Reduced lung function and risk of atrial fibrillation in the Copenhagen City Heart Study. Eur Respir J 2003;21:1012-1016.

-24 Barr RG, Bluemke DA, Ahmed FS, Carr JJ, Enright PL, Hoffman EA, Jiang R, Kawut SM, Kronmal RA, Lima JAC, Shahar E, Smith LJ, Watson KE: Percent emphysema, airflow obstruction, and impaired left ventricular filling. N Engl J Med 2010;362:217-227.

25 Oswald-Mammosser M, Weitzenblum E, Quoix E, Moser G, Chaouat A, Charpentier C, Kessler R: Prognostic factors in $\mathrm{COPD}$ patients receiving long-term oxygen therapy: importance of pulmonary artery pressure. Chest 1995;107:1193-1198.

-26 Zangiabadi A, De Pasquale CG, Sajkov D: Pulmonary hypertension and right heart dysfunction in chronic lung disease. Biomed Res Int 2014;2014:739674.

27 Kawut SM, Poor HD, Parikh MA, Hueper K, Smith BM, Bluemke DA, Lima JAC, Prince MR, Hoffman EA, Austin JHM, Vogel-Claussen J, Barr RG: Cor pulmonale parvus in chronic obstructive pulmonary disease and emphysema: the MESA COPD study. J Am Coll Cardiol 2014;64:2000-2009.

28 Seeger W, Adir Y, Barberà JA, Champion H, Coghlan JG, Cottin V, De Marco T, Galiè N, Ghio S, Gibbs S, Martinez FJ, Semigran MJ, Simonneau G, Wells AU, Vachiéry JL: Pulmonary hypertension in chronic lung diseases. J Am Coll Cardiol 2013;62:D109-D116.

-29 Kario K: Obstructive sleep apnea syndrome and hypertension: ambulatory blood pressure. Hypertens Res 2009;32:428-432.

30 Crinion SJ, McNicholas WT: Sleep-related disorders in chronic obstructive pulmonary disease. Expert Rev Respir Med 2014;8:79-88.

-31 Ross B, McIntosh M, Rodaros D, Hébert TE, Rohlicek CV: Systemic arterial pressure at maturity in rats following chronic hypoxia in early life. Am J Hypertens 2010;23:1228-1233.

-32 Pickering TG, James GD: Ambulatory blood pressure and prognosis. J Hypertens Suppl 1994;12:S29-S33. 
Imaizumi et al.: Lung Disease and Hypertension

33 Imaizumi Y, Eguchi K, Taketomi A, Kario K: Exaggerated blood pressure variability in patients with pneumoconiosis: a pilot study. Am J Hypertens 2014;27:1456-1463.

-34 Auchincloss AH, Diez Roux AV, Dvonch JT, Brown PL, Barr RG, Daviglus ML, Goff DC, Kaufman JD, O’Neill MS: Associations between recent exposure to ambient fine particulate matter and blood pressure in the MultiEthnic Study of Atherosclerosis (MESA). Environ Health Perspect 2008;116:486-491.

-35 Imaizumi Y, Eguchi K, Kario K: Coexistence of PM2.5 and low temperature is associated with morning hypertension in hypertensives. Clin Exp Hypertens 2015, Epub ahead of print.

-36 van Gestel AJ, Kohler M, Clarenbach CF: Sympathetic overactivity and cardiovascular disease in patients with chronic obstructive pulmonary disease (COPD). Discov Med 2012;14:359-368.

-37 Mattace-Raso FUS, van den Meiracker AH, Bos WJ, van der Cammen TJM, Westerhof BE, Elias-Smale S, Reneman RS, Hoeks APG, Hofman A, Witteman JCM: Arterial stiffness, cardiovagal baroreflex sensitivity and postural blood pressure changes in older adults: the Rotterdam Study. J Hypertens 2007;25:1421-1426.

-38 Heindl S, Lehnert M, Criée CP, Hasenfuss G, Andreas S: Marked sympathetic activation in patients with chronic respiratory failure. Am J Respir Crit Care Med 2001;164:597-601.

-39 Macefield VG: Firing patterns of muscle vasoconstrictor neurons in respiratory disease. Front Physiol 2012; $3: 153$.

40 Clarenbach CF, Senn O, Sievi NA, Camen G, van Gestel AJR, Rossi VA, Puhan MA, Thurnheer R, Russi EW, Kohler M: Determinants of endothelial function in patients with COPD. Eur Respir J 2013;42:1194-1204.

-41 van Gestel AJR, Clarenbach CF, Stöwhas AC, Rossi VA, Sievi NA, Camen G, Kohler M: The speed of blood pressure fluctuations in patients with chronic obstructive pulmonary disease. Heart Lung Circ 2014;23:280-286.

42 Japanese Respiratory Society: The Japanese Respiratory Society Guidelines for the Diagnosis and Treatment of COPD, ed 4. Tokyo, Medical Review, 2013.

43 Salpeter S, Ormiston T, Salpeter E: Cardioselective beta-blockers for chronic obstructive pulmonary disease. Cochrane Database Syst Rev 2005;CD003566.

44 Shimamoto K, Ando K, Fujita T, et al; Japanese Society of Hypertension Committee for Guidelines for the Management of Hypertension: The Japanese Society of Hypertension Guidelines for the Management of Hypertension (JSH 2014). Hypertens Res 2014;37:253-390.

45 Schwartzstein RS, Fanta CH: Orally administered nifedipine in chronic stable asthma. Comparison with an orally administered sympathomimetic. Am Rev Respir Dis 1986;134:262-265.

46 Kamp 0, Metra M, Bugatti S, Bettari L, Dei Cas A, Petrini N, Dei Cas L: Nebivolol: haemodynamic effects and clinical significance of combined beta-blockade and nitric oxide release. Drugs 2010;70:41-56.

-47 Hawkins NM, MacDonald MR, Petrie MC, Chalmers GW, Carter R, Dunn FG, McMurray JJV: Bisoprolol in patients with heart failure and moderate to severe chronic obstructive pulmonary disease: a randomized controlled trial. Eur J Heart Fail 2009;11:684-690.

-48 Lainscak M, Podbregar M, Kovacic D, Rozman J, von Haehling S: Differences between bisoprolol and carvedilol in patients with chronic heart failure and chronic obstructive pulmonary disease: a randomized trial. Respir Med 2011;105(suppl 1):S44-S49.

-49 Jabbour A, Macdonald PS, Keogh AM, Kotlyar E, Mellemkjaer S, Coleman CF, Elsik M, Krum H, Hayward CS: Differences between beta-blockers in patients with chronic heart failure and chronic obstructive pulmonary disease: a randomized crossover trial. J Am Coll Cardiol 2010;55:1780-1787.

50 Rutten FH, Zuithoff NA, Hak E, Grobbee DE, Hoes AW: $\beta$-Blockers may reduce mortality and risk of exacerbations in patients with chronic obstructive pulmonary disease. Arch Int Med 2010;170:880-887.

51 Hawkins NM, Virani S, Ceconi C: Heart failure and chronic obstructive pulmonary disease: the challenges facing physicians and health services. Eur Heart J 2013;34:2795-2807.

52 Etminan M, Jafari S, Carleton B, FitzGerald JM: Beta-blocker use and COPD mortality: a systematic review and meta-analysis. BMC Pulm Med 2012;12:48.

53 Hawkins NM, Petrie MC, Macdonald MR, Jhund PS, Fabbri LM, Wikstrand J, McMurray JJ: Heart failure and chronic obstructive pulmonary disease the quandary of beta-blockers and beta-agonists. J Am Coll Cardiol 2011;57:2127-2138.

54 Rialp Cervera G, del Castillo Blanco A, Pérez Aizcorreta O, Parra Morais L: Noninvasive mechanical ventilation in chronic obstructive pulmonary disease and in acute cardiogenic pulmonary edema. Med Intensiva 2014; 38:111-121.

55 Thorens JB, Ritz M, Reynard C, Righetti A, Vallotton M, Favre H, Kyle U, Jolliet P, Chevrolet JC: Haemodynamic and endocrinological effects of noninvasive mechanical ventilation in respiratory failure. Eur Respir J 1997; 10:2553-2559.

56 Global Initiative for Chronic Obstructive Lung Disease (GOLD). Global Strategy for the Diagnosis, Management and Prevention of COPD. 2014. 